\title{
Access to scientific journals
}

SIR-The advance of science depends upon continuous communication among its practitioners. Interchanges of new concepts and laboratory and field data occur at meetings, through personal contacts and through various forms of publication. But many members of the scientific community have only limited contacts with their colleagues, particularly in the developing world where hard currency, and hence travel and scientific journals and books, is difficult to come by. The lack of journals that publish a wide spectrum of important scientific articles, such as Science and Nature, is especially critical. Such publications are necessary stepping stones for innovative and substantial studies.

The lack of exposure to these journals by a large number of scientists became evident to me during a recent sabbatical at the Ruder Boskovic Institute in Yugoslavia. This distinguished institution, with more than eighty scientists and a large number of laboratories outside its central facility in Zagreb, has single subscriptions to both Science and Nature, which are kept under lock and key in the Zagreb Library. Personal subscriptions are out of the question. As a consequence, most investigators are not exposed to the journals in continuous and systematic ways. This situation is repeated over and over again in the developing world.

A second observation in Yugoslavia suggests an interesting solution to the problem. I visited a number of institutions and saw in their libraries a superabundance of periodicals from international agencies such as UNESCO, UNEP, FAO and WHO. Although some were substantial and relevant, the local scientists emphasized that others were of poor scientific quality and of little use. The scientific presses of these organizations are most productive of pages but often not of substance. In addition, many of these publications end up in bureaucratic offices, not in the hands of the scientists for whom they were intended.

A small percentage of the publication costs of these international agencies, if directed to the reproduction and distribution in adequate numbers of articles and reports from Science and Nature to the laboratories and scientific facilities of countries in the developing world, would constitute a major benefit. Clearly, such problems as copyright restrictions could be overcome through effective political action.

Who might bring about such action? The new director general of UNESCO will clearly have ample opportunities for innovative activity. Or perhaps a collusion of scientists of the developing world might push for such a venture. I suspect, how- ever, that activity must be initiated from the top down, not from the bottom up.

EDWARD D. GoldBerg

Scripps Institute of Oceanography,

University of California, San Diego,

La Jolla,

California 92093, USA

\section{Science in Spain}

SIR-Your supplement on "Science in Iberia" (Nature 324, 313-332; 1986) described most of the new aspects of Spanish scientific policy. The national plan for scientific research and technological development will allow up to 1 per cent of gross domestic product to be spent on research and development. This figure, although not large enough to be compared with that in other developed countries, represents some effort by the Spanish government and makes it possible to be reasonably optimistic. Nevertheless, the human factor was not taken into account in your report.

Most researchers believed that the reorganization of science in Spain would result both in an increase in the number of scientists and in a change of the traditional climate, which lacked social stimuli. New appointments have allowed young people to be recruited to the staff of the Consejo Superior de Investigaciones Científicas (CSIC), but it is generally agreed that senior people have hardly been promoted. On the other hand, 18 months after the law for the promotion and general coordination of scientific research and technological development was passed by parliament, salaries of researchers at both the CSIC and the universities continue to be shockingly low - about 30 per cent less than the average salaries of other comparable public employees. This fact was publicly conceded by CSIC's head, Professor Trillas, at a meeting in Madrid last December. The complete reorganization of the CSIC's personnel that is now being carried out would allow a substantial increase in salaries, which should represent only a small economic effort. But the Spanish authorities seem to have chosen to lose this historic opportunity and to ignore the advice of scientific associations and trade unions. This lack of receptiveness is discouraging to many Spanish scientists and could seriously disturb the development of current and future research projects. It would be a great pity if a government that has invested such a great effort in the renaissance of Spanish science were responsible for its failure.

ERnesto Garcia Centro de Investigaciones Biológicas, CSIC,

Velázquez, 144, 28006 Madrid, Spain

\section{Germ-line quandary}

SIR-I find it remarkable that your recent comment on germ-line genetic manipulation (Nature 331, 100; 1988) itself overlooks a very simple practical point, while complaining that "several important and ultimately practical questions have been ducked".

In considering manipulation of the "genomes of early embryos so as to avoid the possibility that unwanted genetic disease will emerge" the writer took as an example the X-linked disorder haemophilia. Clearly, a prequisite for a 'correction' of the mutation by genetic manipulation will be the ability to diagnose the mutation in the early embryo in the first place. From our present knowledge, it seems that both the diagnosis and manipulation would need to be in a preimplantation embryo generated by in vitro fertilization. A carrier for haemophilia has a 50 per cent chance that her male embryo would not have the mutation and the current widely accepted clinical practice of in vitro fertilization generates several preimplantation embryos simultaneously. Thus our future mother-to-be and clinical molecular embryologist will have a stark choice; to be the first to transfer a genetically manipulated human embryo in the hope that the experiment will lead to the birth of a healthy baby, or to select another embryo that does not carry the haemophilia mutation. There seems little doubt from both a practical and an ethical standpoint that embryo selection will win hands down, when helping couples to avoid the transmission of serious genetic disease to their children.

Current legislation in the making recognizes the benefits of preimplantation diagnosis and embryo selection and, it is hoped, will allow, within strict limits, some research into early human embryology. To argue that genetic manipulation of early embryos should not be outlawed without giving any example of potential benefit that could not be better provided by embryo selection is particularly foolish at this time of public debate (and when the British government's white paper on the new embryology is to be debated in parliament). There are many who would wish to stop all embryo research, including studies designed to test the safety of embryo biopsy on which preimplantation diagnosis will depend. Vague claims of benefit without giving clear practical examples will only hasten "the drift into muddle" that your leading article sought to warn us of, and damage the credibility of clinical scientists in the process.

Marcus Pembrey

Mothercare Department of Paediatric

Genetics,

Institute of Child Health,

30 Guildford Street,

London WC1N1EH, UK 